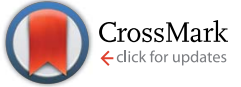

Cite this: RSC Adv., 2017, 7, 16474

Received 10th January 2017

Accepted 6th March 2017

DOI: $10.1039 / c 7 r a 00393 e$

rsc.li/rsc-advances

\section{Improved performance of Schiff based ionophore modified with MWCNT for Fe(II) sensing by potentiometry and voltammetry supported with DFT studies $\uparrow$}

\begin{abstract}
Sanjeev Kumar, ${ }^{a}$ Susheel K. Mittal, ${ }^{* a}$ Navneet Kaur ${ }^{\mathrm{b}}$ and Ravneet Kaur ${ }^{\mathrm{b}}$
A novel potentiometric and voltammetric sensor for creating a cationic response for Fe(II) is introduced. These methods were applied to produce an Fe(॥) selective sensor based on (E)-3-((2-aminoethylimino) methyl)-4H-chromen-4-one (IFE). The influence of variables including the amount of ionophore, plasticizers, anion excluder and multiwalled carbon nanotubes (MWCNTs) on the performance of the potentiometric sensor were investigated. The sensor for Fe(॥) improvised the dynamic linear range $(1 \times$ $10^{-7}$ to $1 \times 10^{-1} \mathrm{~mol} \mathrm{~L}^{-1}$ ) with a slope of $27 \mathrm{mV}$ per decade and a detection limit of $2.5 \times 10^{-8} \mathrm{~mol} \mathrm{~L}^{-1}$. Selectivity of the ion selective electrode improved after modification with MWCNTs. The reduction and oxidation properties of IFE were studied by voltammetric measurements. Differential pulse voltammetry was applied to the optimized electrode and a linear dynamic range from $\left(9.9 \times 10^{-7}\right.$ to $2.9 \times 10^{-5} \mathrm{~mol}$ $\mathrm{L}^{-1}$ ) with a detection limit of $6.13 \times 10^{-8} \mathrm{~mol} \mathrm{~L}^{-1}$ was obtained. The composition and morphology of the modified ion selective electrode were characterized with scanning electron microscopy. The modified electrodes have good selectivity for Fe(॥) ions over a number of metal ions. It was successfully applied for direct determination of Fe(॥) ions in different real life samples. Theoretical calculations also supported the complexation behavior of Fe(॥) with IFE.
\end{abstract}

\section{Introduction}

Iron is the fourth most abundant element in the earth's crust, one of the essential trace elements in the human body and plays a vital role in plant metabolism and in various biological processes. ${ }^{\mathbf{1}}$ The essentiality of both iron(II) and iron(III) for living organisms is well known and in each oxidation state iron plays different major roles in serving as active centers of proteins such as oxidases and reductases, being involved in oxygen transport and photosynthesis. ${ }^{2-6}$ Compared to iron(III), iron(II) is the more soluble form and is required for proper transport of oxygen to tissues by means of hemoglobin and myoglobin. Methemoglobin and myoglobin containing the oxidized form of iron lack the ability to bind to oxygen. ${ }^{7}$ Deficiency of iron in a human being leads to anemia while its excess concentration in the body causes liver and kidney damage (hemochromatosis). ${ }^{8}$ Based on the various functions of iron it is important to determine the traces of iron in medicinal, environmental chemistry and in the various biological process.

${ }^{a}$ School of Chemistry and Biochemistry, Thapar University, Patiala, Punjab 147004, India.E-mail: smittal@thapar.edu

${ }^{b}$ Department of Chemistry, Panjab University Chandigarh, Punjab 160014, India

$\dagger$ Electronic supplementary information (ESI) available. See DOI: 10.1039/c7ra00393e
Numerous analytical techniques have been used for sensing $\mathrm{Fe}(\mathrm{II})$. Conventional techniques such as spectrophotometry, ${ }^{\mathbf{9}, \mathbf{1 0}}$ FAAS (flame atomic absorption spectroscopy) ${ }^{\mathbf{1 1}}$ and ICP-AES (inductively coupled plasma-atomic emission spectrometry $)^{12,13}$ have been used for iron ions detection. These methods are costly, complicated and not convenient for quick online monitoring of Fe(II). Among the various sensing applications, potentiometry and voltammetry are employed for the direct quantification of trace analysis of Iron. Schiff bases, having an azomethine group $-\mathrm{C}=\mathrm{N}-$ are among the most important ligands used in modern coordination chemistry due to their well-known coordinating capability and their rapid exchange kinetics.

The Schiff bases system are known to perform as an efficient donor-bridge-acceptor system. ${ }^{\mathbf{1 4 - 1 7}}$ The Schiff base moiety in the receptor plays key role in host-guest chemistry of IFE with Fe(II). These Schiff bases and their complexes have wide applications in different areas of electrochemistry, ${ }^{18}$ highly selective polymer membrane electrodes, ${ }^{19}$ optical sensors ${ }^{20}$ and other biological probes. ${ }^{21}$

To the best of our knowledge, there is no report available in literature regarding the electrochemical sensing of $\mathrm{Fe}(\mathrm{II})$ using MWCNT as an ion to electron transducer. In this work, a novel $\mathrm{Fe}$ (II) ion selective sensor prepared by the addition of MWCNT in the membrane matrix of ion selective electrode (ISE) in 
presence of anionic additive and plasticizer is proposed. Both the developed potentiometric and voltammetric sensors were successfully applied to detect the Fe(II) ions in pharmaceutical tablets and black tea.

\section{Experimental}

\subsection{Materials}

All reagents and solvents were of analytical reagent grade. Multiwalled carbon nanotubes-COOH (MWCNT-COOH) with 10$30 \mathrm{~nm}$ diameter, 1-10 $\mu \mathrm{m}$ length and $>95 \%$ purity were obtained from Nanoshel (USA) and used as received. High molecular weight polyvinyl chloride (PVC), tetrahydrofuran (THF), sodium tetraphenylborate (NaTPB), various plasticizers such as $o$ nitrophenyl octyl ether (o-NPOE), dibutyl amine (DBA), dioctyl phthalate (DOP) were purchased from Sigma-Aldrich (India) and used as received. Bis (2-ethylhexyl) sebacate (DOS) was purchased from Alpha Aesar (India). Electrolyte tetrabutylammonium hexafluorophosphate was obtained from SigmaAldrich. Sodium hydroxide, hydrogen peroxide, hydrazine, nitric acid, sulphuric acid and perchloric acid were obtained from Sd Fine (India). Metal salt solutions of concentration $0.1 \mathrm{~mol} \mathrm{~L}^{-1}$ were prepared by dissolving metal nitrates in double distilled water and standardized wherever necessary. Working solutions of different concentrations were prepared by serial dilutions.

\subsection{Synthesis}

A $100 \mathrm{~mL}$ round bottom flask was indicted with 4-oxo chromene-3-carbaldehyde $\left(0.174 \mathrm{~g}, 10^{-3} \mathrm{~mol} \mathrm{~L}^{-1}\right)$ and ethane1,2-diamine $\left(0.18 \mathrm{~g}, 3 \times 10^{-3} \mathrm{~mol} \mathrm{~L}^{-1}\right)$ in chloroform as solvent $(40 \mathrm{~mL})$ using a method similar to one reported for Schiff's base formation. ${ }^{22}$ The obtained mixture was stirred at room temperature for 4 hours. Receptor IFE was obtained as yellow precipitates. The precipitates thus obtained were filtered and washed thrice using methanol. The obtained receptor was confirmed using melting point, ${ }^{1} \mathrm{H},{ }^{13} \mathrm{C}$ NMR spectroscopy (Fig. S1 and $\mathrm{S} 2 \dagger$ ) and CHN analysis.

\subsection{Preparation of PVC membranes}

PVC-based membranes were prepared by dissolving different amounts of the ionophore $(E)-3-((2$-aminoethylimino)methyl)$4 H$-chromen-4-one (IFE) provided by our coworkers, anion excluder NaTPB, solvent mediator $o$-NPOE and PVC in $5 \mathrm{~mL}$ of THF. Different components were mixed in terms of weight percentages as per combinations are given in Table 1 . The resulting homogenous mixture was concentrated by evaporating THF and then poured in glass rings placed on smooth glass plates. To obtain a membrane with reproducible characteristics, solvent evaporation was carefully controlled; otherwise, morphology and thickness of membranes show significant variations that may ultimately affect sensor response. Transparent membrane so obtained was removed carefully from the glass plate. A $6 \mathrm{~mm}$ diameter piece of the membrane was cut out and glued to one end of the 'Pyrex' glass tube. The prepared electrode was finally conditioned for $24 \mathrm{~h}$ by soaking in a $0.1 \mathrm{~mol} \mathrm{~L}^{-1} \mathrm{Fe}(\mathrm{II})$ solution. It is known that sensitivity, linearity, and selectivity for a given ionophore depend significantly on the membrane composition and nature of plasticizers used. ${ }^{23}$ Hence, several membranes of varying composition were prepared and investigated. The membrane that gave reproducible results and best performance characteristics was selected for detailed studies. Optimum composition of the membrane with the best performance is given in Table 1.

\subsection{Sample preparation and determination}

Determination of $\mathrm{Fe}$ (II) in pharmaceutical samples. The practical ability of sensor no. 3 was further investigated to determine iron in pharmaceutical samples. Samples of finely ground iron capsules and tablet of known weight were treated with $5 \mathrm{~mL}$ concentrated nitric acid and heated to near dryness under the cover of fuming hood. After cooling, the residue was leached with $1 \mathrm{~mol} \mathrm{~L}^{-1} \mathrm{H}_{2} \mathrm{SO}_{4}$. After filtration, the resulting solution was diluted with $100 \mathrm{~mL}$ distilled water and further analyzed with the proposed electrode and Atomic Absorption Spectroscopy (AAS).

Table 1 Composition and characterization of IFE based membrane electrode

\begin{tabular}{|c|c|c|c|c|c|c|c|c|c|c|c|}
\hline \multirow[b]{2}{*}{ S. no. } & \multicolumn{8}{|c|}{ Composition of membrane (\%w/w) } & \multirow{2}{*}{$\begin{array}{l}\text { Detection limit } \\
\left(\mathrm{mol} \mathrm{L}^{-1}\right)\end{array}$} & \multirow{2}{*}{$\begin{array}{l}\text { Linear range } \\
\left(\mathrm{mol} \mathrm{L}^{-1}\right)\end{array}$} & \multirow{2}{*}{$\begin{array}{l}\text { Slope } \\
\text { (mV per decade) }\end{array}$} \\
\hline & Ionophore & PVC & $o$-NPOE & DBA & DOP & DOS & NaTPB & MW-CNTs & & & \\
\hline 1 & 1 & 33 & 64 & - & - & - & 2 & - & $1.0 \times 10^{-6}$ & $1 \times 10^{-6}$ to $1 \times 10^{-1}$ & 25 \\
\hline 2 & 2 & 33 & 63 & - & - & - & 2 & - & $3.9 \times 10^{-6}$ & $1 \times 10^{-5}$ to $1 \times 10^{-1}$ & 33 \\
\hline 3 & 3 & 33 & 62 & - & - & - & 2 & - & $1.0 \times 10^{-7}$ & $1 \times 10^{-7}$ to $1 \times 10^{-1}$ & 27 \\
\hline 4 & 4 & 33 & 61 & - & - & - & 2 & - & $5.0 \times 10^{-7}$ & $1 \times 10^{-6}$ to $1 \times 10^{-1}$ & 19 \\
\hline 5 & 5 & 33 & 60 & - & - & - & 2 & - & $1.2 \times 10^{-6}$ & $1 \times 10^{-5}$ to $1 \times 10^{-1}$ & 33 \\
\hline 6 & 3 & 33 & - & 62 & - & - & 2 & - & $1.0 \times 10^{-6}$ & $1 \times 10^{-6}$ to $1 \times 10^{-1}$ & 18 \\
\hline 7 & 3 & 33 & - & - & 62 & - & 2 & - & $1.7 \times 10^{-7}$ & $1 \times 10^{-6}$ to $1 \times 10^{-1}$ & 14 \\
\hline 8 & 3 & 33 & - & - & - & 62 & 2 & - & $3.1 \times 10^{-7}$ & $1 \times 10^{-6}$ to $1 \times 10^{-1}$ & 11 \\
\hline 9 & 3 & 33 & 64 & - & - & - & - & - & $1.0 \times 10^{-6}$ & $1 \times 10^{-5}$ to $1 \times 10^{-1}$ & 24 \\
\hline 10 & 3 & 33 & 62 & - & - & - & 2 & 0.5 & $1.6 \times 10^{-6}$ & $1 \times 10^{-5}$ to $1 \times 10^{-1}$ & 27 \\
\hline 11 & 3 & 33 & 62 & - & - & - & - & 1 & $1.5 \times 10^{-5}$ & $1 \times 10^{-4}$ to $1 \times 10^{-1}$ & 20 \\
\hline 12 & 3 & 33 & 62 & & & & 2 & 1 & $2.5 \times 10^{-8}$ & $1 \times 10^{-7}$ to $1 \times 10^{-2}$ & 26 \\
\hline
\end{tabular}


Determination of Fe(II) in black tea. A sample of black tea (1 g) was accurately weighed into a $100 \mathrm{~mL}$ beaker. $10 \mathrm{~mL}$ of nitric acid $\left(2 \mathrm{~mol} \mathrm{~L}^{-1}\right)$ and $4 \mathrm{~mL}$ of perchloric acid $\left(0.1 \mathrm{~mol} \mathrm{~L}^{-1}\right)$ were added to the beaker followed by digestion on a hot plate kept in a fuming hood. After that, neutralization was carried out with $\mathrm{NaOH}\left(1 \mathrm{~mol} \mathrm{~L}^{-1}\right)$ and $1 \mathrm{~mL}$ of $0.01 \mathrm{~mol} \mathrm{~L}^{-1}$ hydrazine as a reducing agent was added to the resulting solution. After filtration and dilution with $100 \mathrm{~mL}$ distilled water, iron content in black tea was determined with the proposed electrode and Atomic Absorption Spectroscopy (AAS).

\subsection{Electrochemical and spectroscopic measurements}

Potentiometric measurement. All potential measurements were performed at an ambient temperature of $25.0 \pm 0.1^{\circ} \mathrm{C}$ with a digital Equip-Tronics potentiometer (EQ-602, accuracy, $\pm 0.1 \mathrm{mV}$, Mumbai, India) and $\mathrm{pH}$ of the solution was monitored simultaneously using Equip-Tronics pH meter (EQ-614, Mumbai, India) and conventional glass $\mathrm{pH}$ electrode. All electromotive force (EMF) measurements were performed using the following electrochemical cell assembly.

$\mathrm{REF} \| \mathrm{Fe}^{2+}$ test solution|ionophore (IFE) membrane $\mid \mathrm{Fe}^{2+}$ $\left(0.1 \mathrm{~mol} \mathrm{~L}^{-1}\right) \| \mathrm{REF}$.

A fixed concentration of $\mathrm{Fe}^{2+}$ was taken as an internal solution $\left(0.1 \mathrm{~mol} \mathrm{~L}^{-1}\right)$ and silver, silver chloride electrode was used as a reference electrode. Performance of the electrodes was investigated by measuring the EMF of primary ion solution, which is prepared with a concentration range of $10^{-9}$ to $10^{-1} \mathrm{~mol} \mathrm{~L}^{-1}$ by serial dilutions. Selectivity values $\left(K_{\mathrm{A}, \mathrm{B}}^{\mathrm{Pot}}\right)$ were evaluated using the 'Fixed Interference Method'. ${ }^{24}$ The initial concentration for the interfering ions in FIM was $10^{-2} \mathrm{~mol} \mathrm{~L}^{-1}$.

Voltammetric measurement. The cyclic voltammetric (CV) and differential pulse voltammetric (DPV) measurements were carried out with potentiostat (Autolab/PGSTAT12/Eco Chemie/ Netherlands) with a three-electrode cell, including a Glassy Carbon working electrode (round disk, diameter $2 \mathrm{~mm}$ ), Pt electrode as counter electrode and $\mathrm{Ag} / \mathrm{Ag}^{+}\left(0.1 \mathrm{~mol} \mathrm{~L}^{-1} \mathrm{AgNO}_{3}\right.$ in DMSO) as reference electrode. The experimental conditions were controlled with NOVA 1.5 software. The CV and DPV studies were conducted in the potential range of $0.80 \mathrm{~V}$ to $-2.00 \mathrm{~V} v s . \mathrm{Ag} / \mathrm{Ag}^{+}$at a scan rate of $0.05 \mathrm{~V} \mathrm{~s}^{-1}$, a pulse amplitude of $0.025 \mathrm{~V}$, the pulse width of $0.05 \mathrm{~s}$ and a pulse period of $0.05 \mathrm{~s}$. Before measurements, surface of the working electrode was polished with 0.05-micron alumina, and residual alumina particles were thoroughly removed by placing the working electrode in an ultrasonic cleaner for 15 minutes, dried and washed with pure acetonitrile. The dimethyl sulphoxide (DMSO) was used as the solvent and tetrabutylammonium hexafluorophosphate (TBHP) $0.1 \mathrm{~mol} \mathrm{~L}^{-1}$ as supporting electrolyte for all the voltammetric measurements. The electrochemical measurements were carried out at a temperature of $25.0 \pm 1{ }^{\circ} \mathrm{C}$. In all experiments, the test solutions were deaerated by a stream of nitrogen gas purging through the solution for at least 5 minutes.

The UV-visible spectral studies were recorded on Analytic Jena Specord PC 205 spectrophotometer with a quartz cuvette (path length, $1 \mathrm{~cm}$ ). ${ }^{1} \mathrm{H}$ NMR spectra were recorded using a JEOL spectrometer operating at $400 \mathrm{MHz}$ and ${ }^{13} \mathrm{C}$ NMR spectra were recorded at $100 \mathrm{MHz}$. Surface morphology studies were carried out using a JSM-6510LV field emission scanning electron microscope. Elemental analysis of synthesized ionophore was done using Energy Dispersive X-ray (EDX) spectroscopy using INCA x-act Oxford instrument.

\subsection{Computational details}

Density functional theory (DFT) calculations were carried out with the GAUSSIAN 03W package. Full-unconstrained geometry optimization of (E)-3-((2-aminoethylimino)methyl)-4Hchromen-4-one (IFE) was carried out using B3LYP/6-31G level of theory while metal complexation studies were carried out using LAN2DZ method using basis sets B3LYP/6-31G. A solvent effect has been included in metal complexation studies through the use of IEFPCM model. Gas-phase structure was then used as starting point for further geometry optimization in the IEFPCM approach.

\section{Results and discussion}

A new ionophore (IFE) based on chromen as the basic molecule was synthesized with an aliphatic chain containing amine and imine groups substituted at ortho position to the keto group of pyran ring. The molecule was targeted as an open-ended pseudo cyclic ring where two nitrogen atoms and the ethereal oxygen would form a pseudo cavity to host some transition metal ions. On the basis of hard-soft acid-base concept, $\mathrm{N}$ being a soft base would preferably capture transition metal ions as soft acids. This molecule was studied for its voltammetric, potentiometric and spectrophotometric characteristics supported with DFT calculations, to study its potential as a receptor molecule with a tendency to exhibit host-guest chemistry with target metal ions.

\subsection{Synthesis and characterization of IFE}

Receptor IFE was synthesized by condensation reaction between the reactants 4-oxo chromene-3-carbaldehyde and ethane-1,2diamine using chloroform as a solvent. The reaction was carried out at room temperature, with continuous stirring for $4 \mathrm{~h}$ (Fig. 1). The completion of the reaction i.e. formation of Schiff's base is indicated by the formation of yellow precipitate<smiles>CC1(C)C2C3C(c4ccc5occ(C=NCCN)c(=O)c5c4)C4C3C2C41</smiles>

Fig. 1 Scheme for synthesis of receptor IFE. 


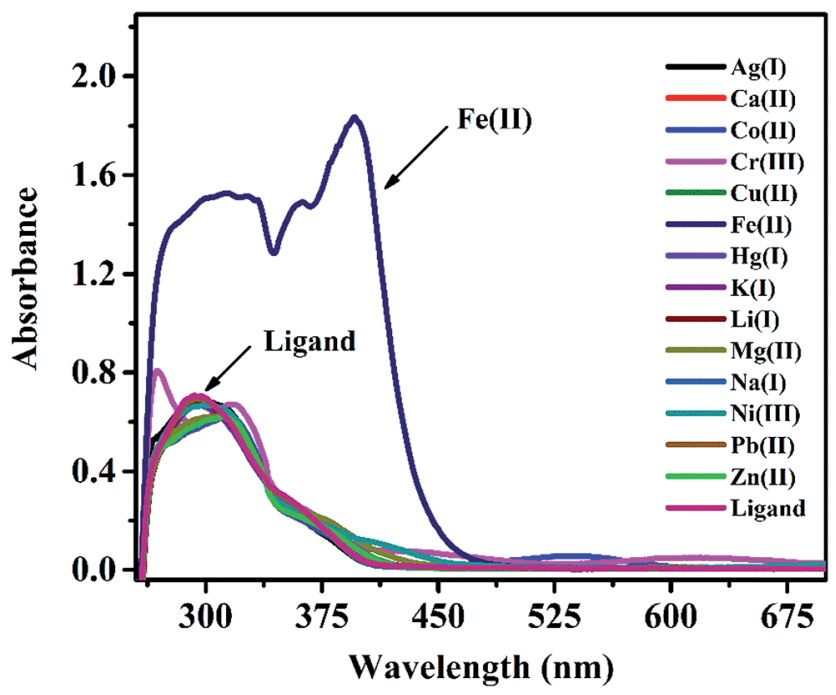

Fig. 2 UV-vis spectral changes of IFE $\left(2 \times 10^{-5} \mathrm{~mol} \mathrm{~L}^{-1}\right)$ in presence of different metal ions.

in the reaction mixture. The precipitates were filtered and washed thrice using methanol, having a yield of $92.05 \%$. Mp $\geq$ $165{ }^{\circ} \mathrm{C} ;{ }^{1} \mathrm{H}$ NMR $\left(400 \mathrm{MHz}, \mathrm{CDCl}_{3}-\mathrm{DMSO}-d_{6}\right) \delta 2.97\left(\mathrm{t}, 2 \mathrm{H}, \mathrm{CH}_{2}\right.$ ), 3.44 (t, 2H, $\mathrm{CH}_{2}$ ), 5.11 (br, 2H, $\mathrm{NH}_{2}$ ), 6.87 (m, 2H, Ar-H), 7.37 (d, 1H, Ar-H), 7.59 (s, 1H, Ar-H), 7.77 (d, 1H, Ar-H), 8.43 (s, 1H, Schiff base); ${ }^{13} \mathrm{C}$ NMR (100 $\left.\mathrm{MHz}, \mathrm{CDCl}_{3}-\mathrm{DMSO}-d_{6}\right) \delta 45.84$, $56.25,118.49,121.29,123.11,125.09,126.74,130.52,136.43$, 149.17, 162.40, 181.26; CHN analysis: expected C: $66.65 \%, \mathrm{H}$ : $5.59 \%$, N: $12.96 \%$, found C: $66.60 \%$, H: $5.51 \%$; N: $12.92 \%$.

\subsection{UV-vis study}

In a preliminary spectrophotometrical study, experiments were carried out with IFE on UV-vis spectrophotometer to know if it forms any complex with metal ions. UV-vis spectra of IFE (Fig. 2) were recorded in the presence of a number of metal ions like $\mathrm{Cu}^{2+}, \mathrm{Ag}^{+}, \mathrm{Fe}^{3+}, \mathrm{Cd}^{2+}, \mathrm{Co}^{2+}, \mathrm{Cr}^{3+}, \mathrm{K}^{+}, \mathrm{Mg}^{2+}, \mathrm{Ca}^{2+}, \mathrm{Ni}^{2+}, \mathrm{Zn}^{2+}, \mathrm{Fe}^{2+}$ in DMSO medium. As seen from the Fig. 2, the major absorption band of IFE was observed at $295 \mathrm{~nm}$ while a new peak appeared at $395 \mathrm{~nm}$ due to the interaction of $\mathrm{Fe}(\mathrm{II})$ by IFE, while no significant changes were observed with all the other metal ions. Due to this ability, we decided to incorporate IFE into a PVC membrane sensing element for monitoring the metal ion $\mathrm{Fe}(\mathrm{II})$.

\subsection{Factors affecting performance of the $\mathrm{Cu}^{2+}$ ion selective electrode}

3.3.1 Effect of composition. It is well known that selectivity and sensitivity of an ion selective electrode depend on the properties of plasticizer, nature of solvent mediator, additive and the amount of ionophore used. ${ }^{25}$ The ionophore IFE tends to form a stable complex with $\mathrm{Fe}(\mathrm{II})$ by coordinating with nitrogen atom of the ligand. IFE is soluble in organic solvents and insoluble in water, therefore this ionophore was used as a sensing element in PVC membrane electrode. For the study of composition, twelve newly designed ISEs (designated as ISE no. 1-12) were fabricated using the ionophore IFE, $o$-NPOE, DBA,
DOP and DOS, as the plasticizer and NaTBP (50 mol\%) as the anionic additive and the results were summarized in Table 1. We found that the sensitivity and linearity of the electrode response reached their best when $3.0 \%$ of ion carrier was used. Below this percentage and further addition of ionophore, however, resulted in a diminished and sluggish response of the electrode, most probably due to possible saturation of the membrane.

It is established that plasticizer which is used in the preparation of ion selective membrane should exhibit high lipophilicity, polarity, viscosity, high capacity to dissolve the substrate and adequate dielectric constant of the plasticizer. Thus, addition of plasticizer will improve the sensitivity and selectivity of the ion selective electrode. ${ }^{26}$

Effects of plasticizer on performance characteristics of the membrane electrode have also been studied. The use of plasticizers gives some permeable properties to the paste and may improve the mechanical stability of the sensor. ${ }^{27}$ It can be seen in Table 1 (no. $3,6-8$ ) that $o$-NPOE is more effective solvent mediator than DBA, DOS and DOP for the electrode due to its large dielectric constant. ${ }^{28,29}$ The high dielectric constant of $o$ NPOE was one of the reasons for low detection limit of the electrode as $1.0 \times 10^{-7} \mathrm{~mol} \mathrm{~L}^{-1}$. Thus, $o$-NPOE was chosen as the best plasticizer for the working electrode. In the absence of NaTPB, the membrane did not follow a Nernstian response but a good Nernstian slope was observed with the presence of $2 \%$ NaTBP. The main function of the lipophilic salt is to enhance the ion selective membrane permselectivity (in order to enhance Nernstian response), to improve sensing selectivity (by defining the ratio of complexed to uncomplexed ionophore concentration in the membrane), and to reduce the bulk membrane resistance. ${ }^{30,31}$ Alternatively, a highly accessible surface area with a narrow distribution size, excellent electrical conductivity, and high stability of MWCNT attract the authors to explore the performance of the iron(II) electrode. As shown in Table 1 (no. 12) and represented in Fig. 3, the electrode doped with $1 \%$

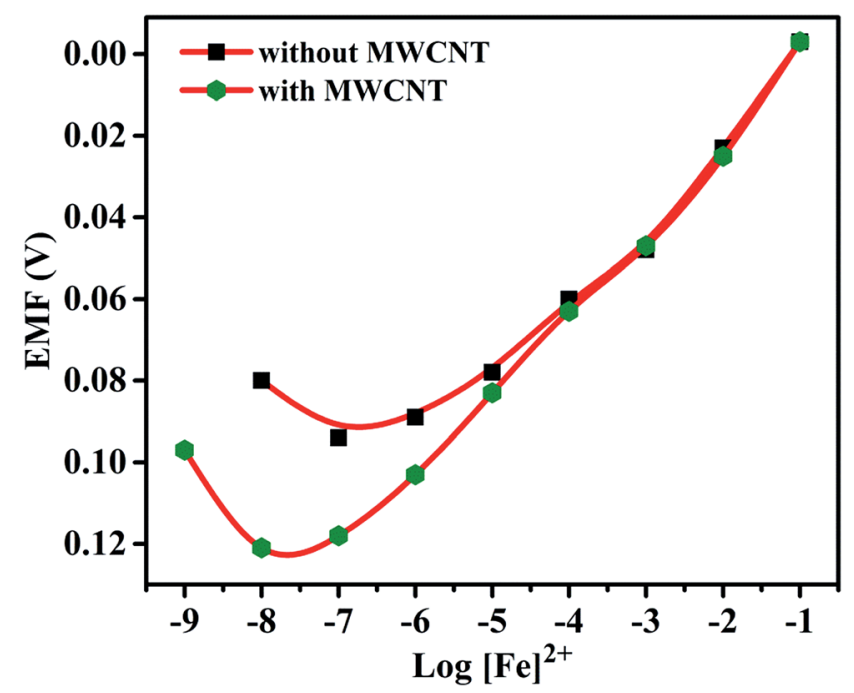

Fig. 3 Calibration curve for Fe(॥)-selective electrode without MWCNTs and with MWCNTs (1\%). 
MWCNT showed enhanced sensitivity observed by the lower detection limit, $2.5 \times 10^{-8} \mathrm{~mol} \mathrm{~L}^{-1}$ compared with its analogue without MWCNT (no. 3).

3.3.2 Effect of $\mathbf{p H}$. The effect of $\mathrm{pH}$ on the electrode response was investigated using $1.0 \times 10^{-3} \mathrm{~mol} \mathrm{~L}^{-1} \mathrm{Fe}(\mathrm{II})$ at different $\mathrm{pH}$. Nitric acid and sodium hydroxide were used to change the $\mathrm{pH}$ of the test solution. Potential response of the electrode was plotted against $\mathrm{pH}$ of the solution as shown in Fig. S3. $\uparrow$ Studies indicate the electrode response is independent of the $\mathrm{pH}$ test solution in the range of $\mathrm{pH}$ 2.5-6.0. Potential changes in $\mathrm{pH}$ less than 2.0 presumably are due to the instability of the ionophore due to protonation of nitrogen. Also, at $\mathrm{pH}$ higher than 7.0 intensive changes in potential are likely due to the sensor response to hydroxide ions.

Table 2 Selectivity coefficient values for the proposed electrodes (EL no. 3 and EL no. 12)

\begin{tabular}{lll}
\hline & \multicolumn{2}{l}{$\log K_{\mathrm{A}, \mathrm{B}}^{\mathrm{Pot}}$} \\
\cline { 2 - 3 } $\begin{array}{ll}\text { Interfering } \\
\text { ions }\end{array}$ & $\begin{array}{l}\text { Electrode no. 3 } \\
\text { without MWCNTs }\end{array}$ & $\begin{array}{l}\text { Electrode no. 12 } \\
\text { with MWCNTs (1\%) }\end{array}$ \\
\hline $\mathrm{Fe}^{2+}$ & 0.00 & 0.00 \\
$\mathrm{Ca}^{2+}$ & -1.64 & -2.60 \\
$\mathrm{Mg}^{2+}$ & -2.45 & -2.69 \\
$\mathrm{~K}^{+}$ & -2.61 & -2.00 \\
$\mathrm{Cu}^{2+}$ & -3.00 & -3.00 \\
$\mathrm{Fe}^{3+}$ & -4.00 & -4.33 \\
$\mathrm{Cr}^{3+}$ & -3.06 & -3.66 \\
$\mathrm{Co}^{2+}$ & -3.09 & -3.10 \\
$\mathrm{Ni}^{2+}$ & -1.20 & -1.60 \\
$\mathrm{Zn}^{2+}$ & -2.69 & -3.94 \\
$\mathrm{Ag}^{+}$ & -0.44 & -3.00 \\
$\mathrm{~Pb}^{2+}$ & -1.17 & -1.88
\end{tabular}

3.3.3 Response time. For any ion selective electrode, dynamic response time is one of the most important significant factor in analytical applications. The response time of the electrode is the time required to attain $90 \%$ of final steady potential value of the electrodes after successive immersion in $\mathrm{Fe}(\mathrm{II})$ solution, each having a 10 fold difference in concentration. In this study response time of the electrode was measured by changing the $\mathrm{Fe}(\mathrm{II})$ concentration ranging from $10^{-8} \mathrm{M}$ to $10^{-2} \mathrm{~mol} \mathrm{~L}^{-1}$. The potential versus time traces are shown in Fig. S4. $\dagger$ As can be seen from the graph that potential response for electrode no. 3 reached the equilibrium in a short response time of $<15 \mathrm{~s}$ and remain stable for $3 \mathrm{~min}$ after which the divergence was recorded. Whereas, with the addition of MWCNT in the polymer matrix, the response time for electrode no. 12 reached the equilibrium $5 \mathrm{~s}$ earlier due to the high electrical conductivity of MWCNT.

3.3.4 Selectivity coefficient. The selectivity of ion selective electrode is one of the most important characteristics, which explain the ability of the electrode to respond to primary ion respect to other interfering ions. In the present study, the selectivity coefficient of the sensor towards different interfering foreign cations was evaluated with the help of fixed interference method (FIM) recommended by IUPAC. ${ }^{32}$ In the fixed interference method, the selectivity coefficient was evaluated from the measurement of potential response in solutions containing fixed concentration of interfering ion, $a_{\mathrm{B}}\left(2 \times 10^{-3} \mathrm{~mol} \mathrm{~L}^{-1}\right)$ and varying amount of primary ions (Fe(II)), $a_{\mathrm{A}}\left(2 \times 10^{-8}\right.$ to $2 \times$ $\left.10^{-1} \mathrm{~mol} \mathrm{~L}^{-1}\right)$. At the intersection of the extrapolated curve of the potential versus logarithm of the activity of the primary ion, the value of $a_{\mathrm{A}}$ in the presence of a diverse ion was calculated that is used to calculate $\left(K_{\mathrm{A}, \mathrm{B}}^{\mathrm{Pot}}\right)$ according to eqn (1):
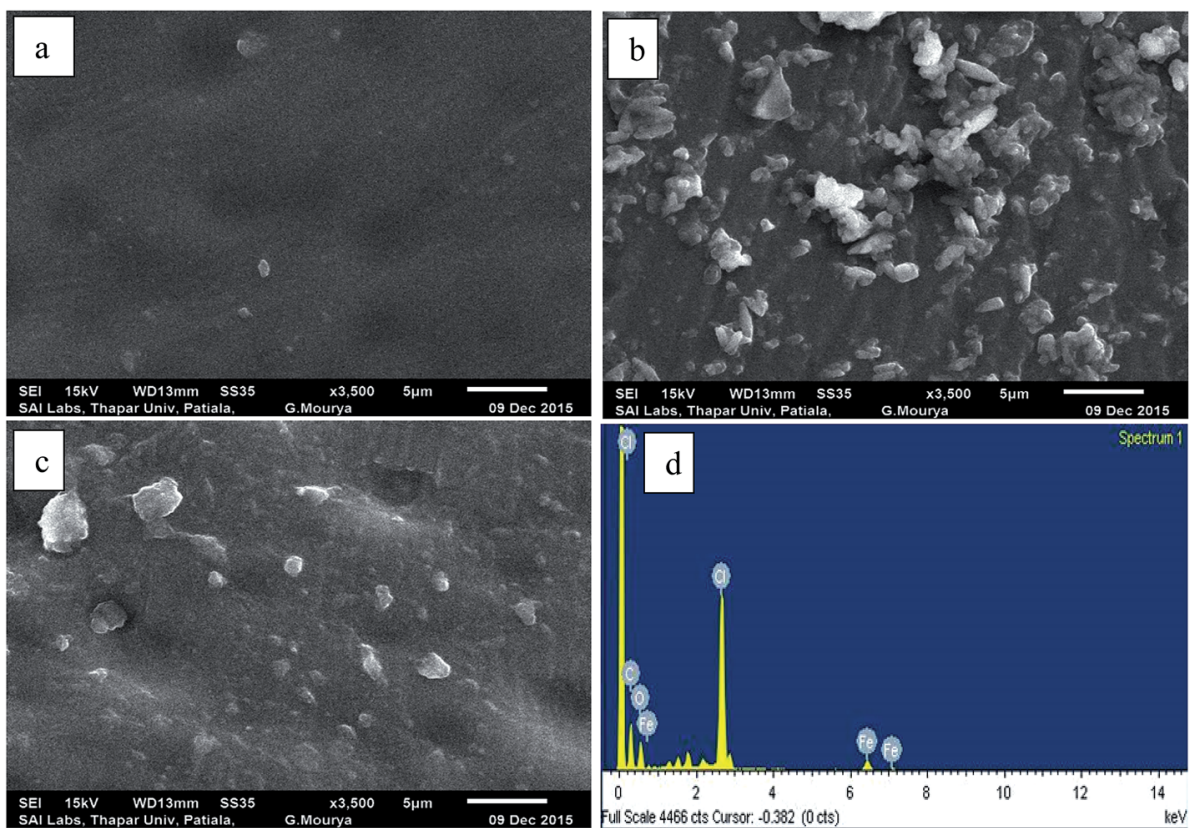

Fig. 4 (a) SEM images for the Fe $\mathrm{F}^{2+}-$ ISE before (b) and after the incorporation of $1 \%$ MWCNTs. (c) After the reaction with iron ions at 3500 magnification factor, respectively and (d) EDX analysis for the same electrode after sorption with iron solution. 


$$
K_{\mathrm{A}, \mathrm{B}}^{\mathrm{Pot}}=\frac{a_{\mathrm{A}}}{a_{\mathrm{B}} \frac{Z_{\mathrm{A}}}{Z_{\mathrm{B}}}}
$$

The selectivity coefficients of electrodes no. 3 and 12 are given in Table 2 . For electrode no. 3 , all the selectivity values are $<1$ except for $\mathrm{Fe}^{2+}$, while the values of all the interfering cations in case of electrode no. 12 are also less than one and much lower than electrode no. 3 for some cations indicating that these cations have a negligible effect on the functioning of proposed electrodes.

3.3.5 Surface characterization of the membrane electrode. To study surface morphology of the membrane, scanning electron microscopic study was done at different stages of its development. Results show that the membrane before adding MWCNT had a smooth surface with small surface defects (Fig. 4(a)). By incorporation of MWCNTs to the membrane matrix, most of the MWCNTs were in the form of small bundles or single tubes. It can be seen that MWCNTs were distributed on the surface of the electrode with special three-dimensional structures (Fig. 4(b)). The EDX spectrum of IFE (Fig. 4(d)) indicated the presence of $\mathrm{Fe}, \mathrm{O}$ and $\mathrm{C}$ in the membrane matrix. The EDX spectrum of the surface of the electrode after dipping in iron solution is a sign of the successful reaction of the titled ionophore with the $\mathrm{Fe}^{2+}$ ions at the electrode surface.

\subsection{Voltammetric discussion}

In the cyclic voltammogram of IFE, there are three weak anodic peaks at $-0.39 \mathrm{~V},-0.12 \mathrm{~V}$ and $0.2 \mathrm{~V}$, in addition to a relatively stronger peak at $-1.0 \mathrm{~V}$. The stronger peak is due to the supporting electrolyte using glassy carbon electrode as a working electrode. The potential was applied at a scan rate of $50 \mathrm{mV} \mathrm{s}^{-1}$. The anodic peaks identified in Fig. 5 as 1, 2 and 3 resulted from the anodic reactions. The most easily oxidizable species is lone pair on $\mathrm{N}$ atom of the terminal amine group which shows anodic peak at the lower applied potential i.e. at $-0.3 \mathrm{~V}$ followed

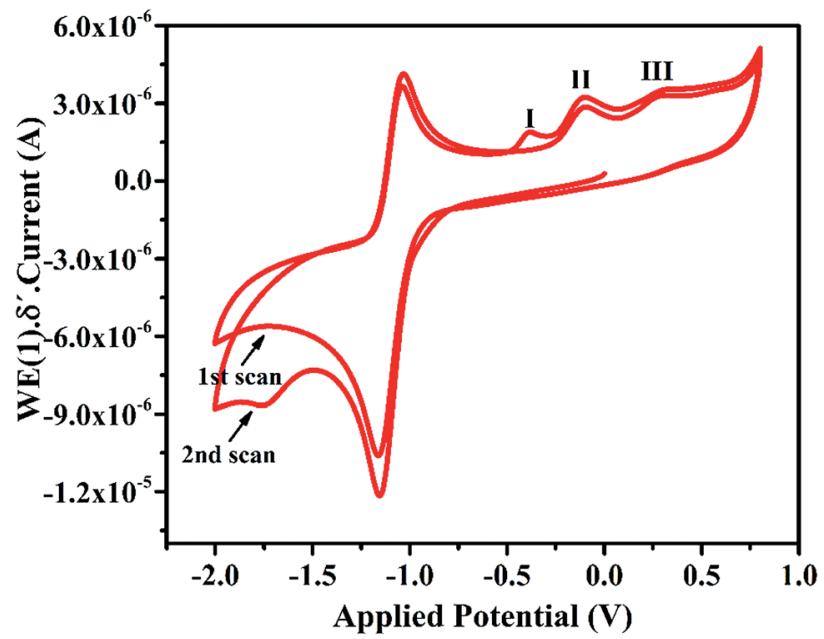

Fig. 5 Cyclic voltammogram of $5 \times 10^{-4} \mathrm{~mol} \mathrm{~L}^{-1}$ IFE at glassy carbon electrode in DMSO, $0.1 \mathrm{~mol} \mathrm{~L}^{-1} \mathrm{TBHP}$. Scan rate: $50 \mathrm{mVs}^{-1}$. by the peaks at $-0.1 \mathrm{~V}$ and $+0.2 \mathrm{~V}$ respectively due to $\mathrm{N}$ atom of imine group and the oxygen atom of pyran ring. For the purpose of further characterization and applications of the ionophore in the anodic DPV, the peak maxima at $-0.12 \mathrm{~V}$ has been chosen as a model peak.

3.4.1 Scan rate. In order to understand the process involved in electrochemical oxidation of IFE at the glassy carbon electrode surface, peak currents of anodic waves were plotted against the square root of scan rate (Fig. S5(a) $\dagger$ ). A linear relationship was found (Fig. S5(b)†) between peak current $I_{\mathrm{pa}}$ and the square root of scan rate. This phenomenon indicates that the oxidation of the IFE is controlled by its diffusion towards the electrode surface. The anodic peak potential moves slightly in a positive direction when scan rate increases from $10 \mathrm{mV} \mathrm{s}^{-1}$ to $130 \mathrm{mV} \mathrm{s}^{-1}$ implying that the electron transfer is not very fast.

3.4.2 Complexation with metal ion. Experiments were conducted using voltammetric scans of IFE in presence of a number of transition metal ions. It is expected that on complexation with the metal ion, the primary and secondary nitrogen atoms on the aliphatic chain attached to the chromen ring would form a pseudo cavity with the oxygen atom of pyran ring. As a result of the complexation, lone pair on the imine nitrogen would coordinate with the metal ion and does not remain available for any anodic peak. On studying the voltammogram of IFE with each metal ion of the selected group, the peak in anodic region of CV was found quenched completely in presence of $\mathrm{Fe}(\mathrm{II})$ ions as shown in Fig. S6, $\uparrow$ whereas, with most of other metal ions the anodic peaks are still observed clearly, indicating selective complexation of IFE with Fe(II).

3.4.3 Voltammetric study of IFE in presence of some transition metal ions. Differential pulse voltammogram of IFE were drawn separately with each transition metal ions like $\left(\mathrm{K}^{+}\right.$, $\mathrm{Mg}^{2+}, \mathrm{Ca}^{2+}, \mathrm{Cr}^{3+}, \mathrm{Fe}^{3+}, \mathrm{Fe}^{2+}, \mathrm{Co}^{2+}, \mathrm{Ni}^{2+}, \mathrm{Cu}^{2+}, \mathrm{Zn}^{2+}, \mathrm{Ag}^{+}, \mathrm{Hg}^{2+}$ and $\mathrm{Pb}^{2+}$ ). As seen from the Fig. 6 there is no major shift in the anodic peak at $-1.0 \mathrm{~V}$ with all the tested metal species except with $\mathrm{Fe}(\mathrm{II})$ for which the ligand shows new peaks at $-0.2 \mathrm{~V}$ and $-1.0 \mathrm{~V}$. This is a unique observation in DPV plots as well, which

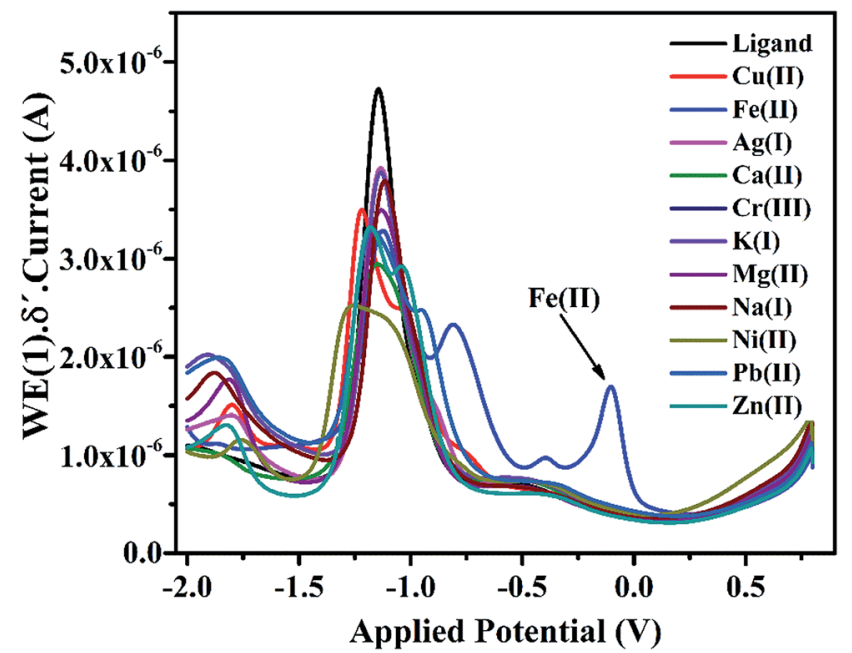

Fig. 6 Differential pulse voltammogram of IFE in the presence of different metal ions. 


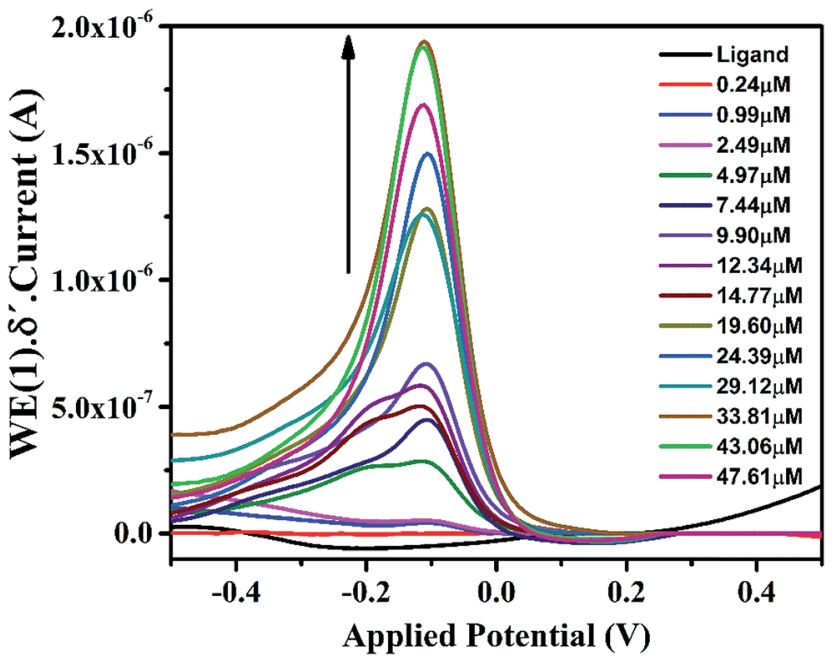

Fig. 7 Cathodic DPV of $5.0 \times 10^{-4} \mathrm{~mol} \mathrm{~L}^{-1}$ IFE in the presence of increasing amount of $\mathrm{Fe}(॥)$ ions in DMSO; electrolyte $0.1 \mathrm{~mol} \mathrm{~L}^{-1} \mathrm{TBHP}$; pulse amplitude of $0.05 \mathrm{~V}$; scan rate $0.05 \mathrm{~V} \mathrm{~s}^{-1}$ within potential range of 0.50 to $-0.50 \mathrm{~V} v \mathrm{~s}$. $\mathrm{Ag} / \mathrm{Ag}^{+}$.

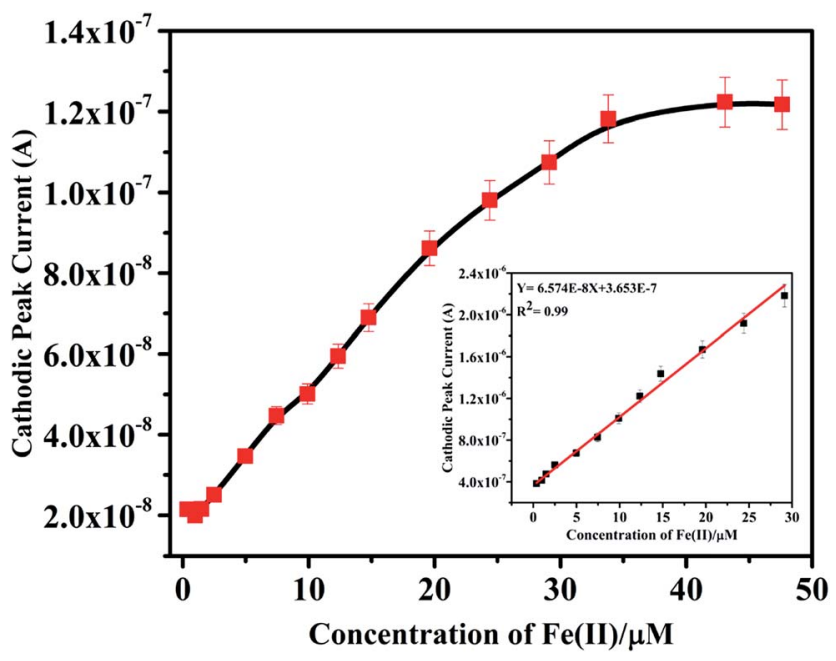

Fig. 8 Calibration plots between concentration and corresponding current for IFE in electrolyte TBAP $\left(0.1 \mathrm{~mol} \mathrm{~L}^{-1}\right)$, pulse amplitude of $0.05 \mathrm{~V}$; scan rate $0.05 \mathrm{~V} \mathrm{~s}^{-1} \mathrm{vs}$. $\mathrm{Ag} / \mathrm{Ag}^{+}$.

indicates a strong complexing ability of IFE with Fe(II). The experiment of ligand complexation was repeated at least 5 times to confirm the observation.
3.4.4 Titration curve of IFE. In order to confirm application potential of the ligand and its kinetic response to the electrode differential pulse voltammograms were recorded on successive additions of small amounts of $\mathrm{Fe}(\mathrm{II})$ to carry out voltammetric titration of IFE with Fe(II) (Fig. 7). It was observed that on each addition of the titrant volume a spontaneous increase in current was noticed (at a scan rate of $50 \mathrm{mV} \mathrm{s}^{-1}$ ). The cathodic current stabilized after increasing linearly until the metal-ligand ratio reached $1: 1$. No further increase in current was noticed indicating 1:1 stoichiometry of the complex with the fast and efficient response of the electrode without any lag in applied potential.

Further studies on the compound were carried out to seek its quantitative application by using standard calibration method. DPV of IFE were recorded with different concentrations of $\mathrm{Fe}(\mathrm{II})$. The plots of current magnitude plotted against different concentrations of Fe(II) are shown in (Fig. 8). The calibration curve is a linear straight line with a slope of $6.57 \times 10^{-8} \mathrm{~mol} \mathrm{~L}^{-1}$ and a standard deviation of $1.85 \times 10^{-9} \mathrm{~mol} \mathrm{~L}^{-1}$. Although another new peak was observed in presence of $\mathrm{Fe}(\mathrm{II})$ at $-0.8 \mathrm{~V}$ but the peak at $-0.1 \mathrm{~V}$ was selected for quantitative applications because of well-defined shape. It was observed that the current magnitude increased linearly with the concentration of metal ion. A good linearity was found in the concentration range of 9.9 $\times 10^{-7} \mathrm{~mol} \mathrm{~L}^{-1}$ to $2.9 \times 10^{-5} \mathrm{~mol} \mathrm{~L}^{-1} \mathrm{Fe}(\mathrm{II})$ with a correlation coefficient of 0.99 . At a concentration higher than $2.9 \times$ $10^{-5} \mathrm{~mol} \mathrm{~L}^{-1}$ deviation from the linearity occurred due to saturation at the electrode surface and detection limit of IFE was estimated as $6.13 \times 10^{-8} \mathrm{~mol} \mathrm{~L}^{-1}$.

\subsection{Theoretical calculations}

To better understand nature of the coordination of $\mathrm{Fe}(\mathrm{II})$ with IFE, energy-optimized structures of IFE and its corresponding Fe(II) complexes (Fig. 9) were obtained from density functional theory (DFT) calculations at the B3LYP level using 6-31G basis set for simple ionophore (IFE) and metal complexes using the Gaussian 03W software.

The spatial distributions and orbital energies of highest occupied molecular orbital (HOMO) and lowest unoccupied molecular orbital (LUMO) of IFE and its complex IFE-Fe(II) were also determined (Fig. 10). The energy gap between HOMO and LUMO energy levels is an important parameter in determining the reactivity of the molecule. ${ }^{33}$ Quantitatively, the calculated values of energy of HOMOs and LUMOs are $-0.210 \mathrm{eV}$ and

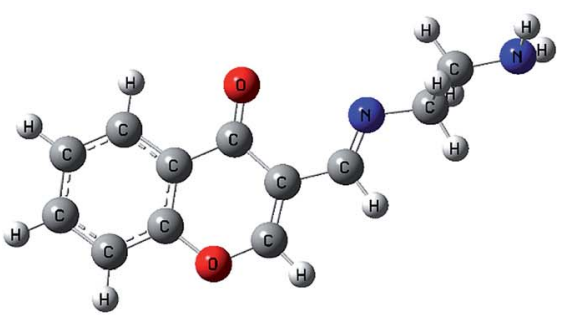

(a)

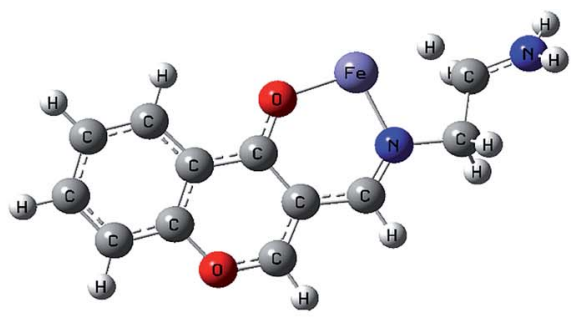

(b)

Fig. 9 DFT computed optimized structure of receptor IFE (a) and its complex with Fe(॥) (b). 
(a)

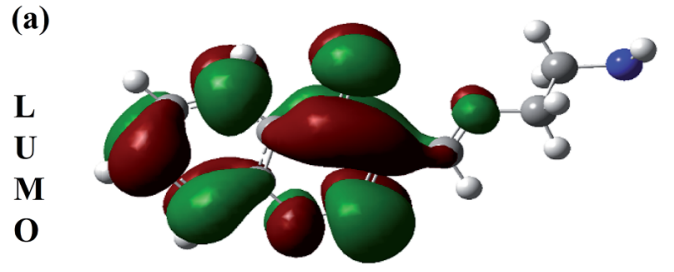

$\Delta E=0.146 \mathrm{eV}$ (b)

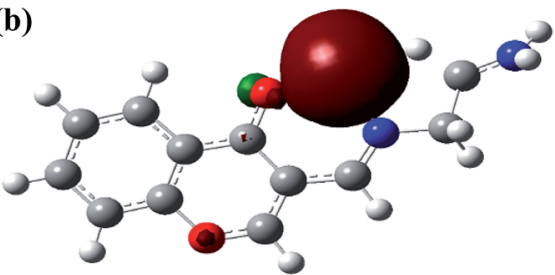

$$
\Delta E=0.093 \mathrm{eV}
$$
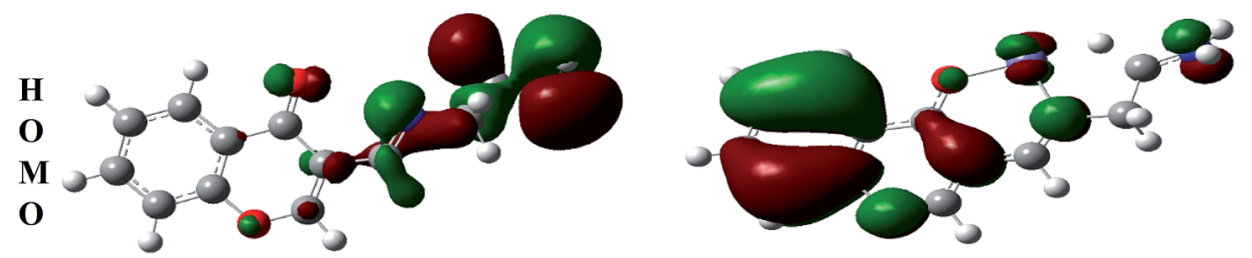

Fig. 10 DFT computed HOMO and LUMO diagram of (a) IFE and its (b) IFE-Fe(॥) complex.

$-0.063 \mathrm{eV}$ for the free ligand (a) and $-0.501 \mathrm{eV}$ and $-0.408 \mathrm{eV}$ for the Fe(II) complex (b). The energy difference between the LUMO and HOMO is defined as the band gap energy $\left(E_{g}\right)$, which can be calculated as

$$
E_{\mathrm{g}}=E_{\mathrm{LUMO}}-E_{\mathrm{HOMO}}
$$

According to DFT calculations, the values of $E_{\mathrm{g}}$ in gaseous phase for the proposed free ligand and its $\mathrm{Fe}^{2+}$ complex are $0.146 \mathrm{eV}$ and $0.093 \mathrm{eV}$, respectively, while during solvation process with DMSO, the $E_{\mathrm{g}}$ for IFE- $\mathrm{Fe}^{2+}$ complex alters to $0.102 \mathrm{eV}$. The results clearly indicate that the binding of $\mathrm{Fe}(\mathrm{II})$ to IFE lowered the HOMO-LUMO energy gap and stabilized the

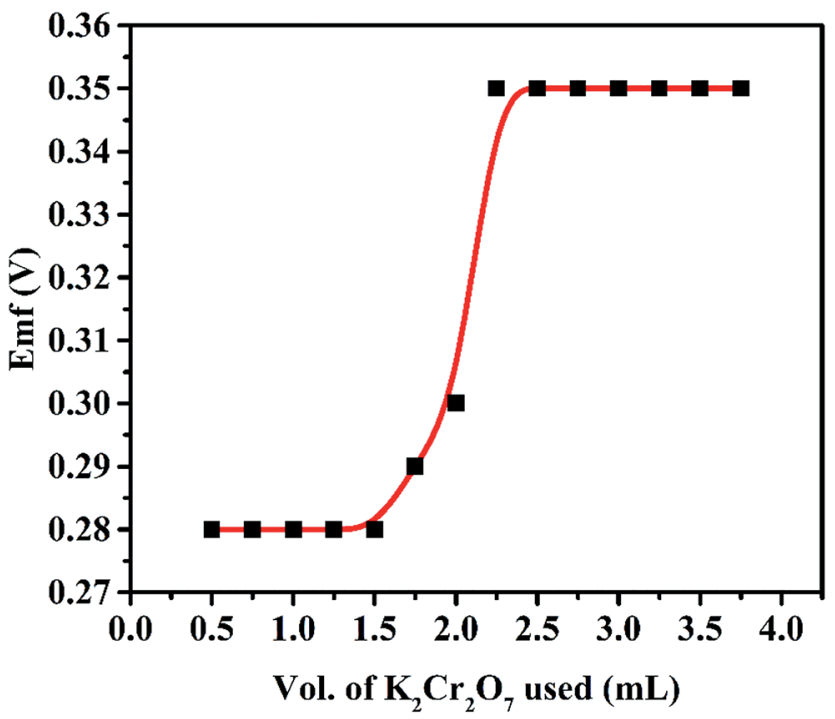

Fig. 11 Potentiometric titration of $20 \mathrm{~mL}$ of Fe(॥) $\left(1 \times 10^{-3} \mathrm{~mol} \mathrm{~L}^{-1}\right)$ with $\mathrm{K}_{2} \mathrm{Cr}_{2} \mathrm{O}_{7}\left(1 \times 10^{-2} \mathrm{~mol} \mathrm{~L}^{-1}\right)$. system through electron transfer. Thus, they show a favorable complexation according to proposed coordination.

The binding stoichiometry for IFE and Fe(II) was further analyzed by plotting the Job's plot (Fig. S7†). The Job's function $A_{\text {Job }}$ is calculated according to the equation $A_{\text {Job }}=(1-X) A_{0}-A$. The maximum absorbance at a molar fraction of 0.5 clearly reveals the formation of a Fe(II) complex in $1: 1$ stoichiometry. In view of the experimental evidence, the 3-D molecular structure and charge transfer process occurred during the binding of $\mathrm{Fe}(\mathrm{II})$ by IFE. It was investigated by density functional theory (DFT) calculations by applying the B3LYP functional, and the basis sets 6-31G for Fe atom available in the computational code Gaussian 03W as shown in Fig. 9.

\subsection{Analytical application}

To evaluate the utility of this membrane electrode, potentiometric titration was carried out for the determination of end point. For this, $20 \mathrm{~mL}$ of $1 \times 10^{-3} \mathrm{~mol} \mathrm{~L}^{-1}$ of Fe(II) was titrated against $1 \times 10^{-2} \mathrm{~mol} \mathrm{~L}^{-1}$ of $\mathrm{K}_{2} \mathrm{Cr}_{2} \mathrm{O}_{7}$ (Fig. 11). The titration plot was obtained in sigmoid shape and a sharp breakpoint exhibit a $1: 1$ stoichiometry of the Fe(II) complex. After the end point, the potential response remains constant due to decrease in the concentration of $\mathrm{Fe}(\mathrm{II})$ ion. In order to examine the practical

Table 3 Result of three replicate determination of Fe(॥) in various real life samples

\begin{tabular}{lll}
\hline & \multicolumn{2}{l}{ Concentration $\left(\mathrm{mol} \mathrm{L}^{-1}\right)$} \\
\cline { 2 - 3 } Sample & Proposed method & AAS method \\
\hline Multivitamin tablet & $9.2 \times 10^{-4}( \pm 3 \%)$ & $9.0 \times 10^{-4}( \pm 2 \%)$ \\
Ferrous sulphate tablet & $1.2 \times 10^{-3}( \pm 3 \%)$ & $1.2 \times 10^{-3}( \pm 2 \%)$ \\
Iron capsule & $1.3 \times 10^{-2}( \pm 1 \%)$ & $1.2 \times 10^{-2}( \pm 2 \%)$ \\
Black tea & $2.4 \times 10^{-4}( \pm 2 \%)$ & $2.5 \times 10^{-4}( \pm 3 \%)$
\end{tabular}


Table 4 Comparison of the proposed method with the previously reported Fe(॥) selective electrodes

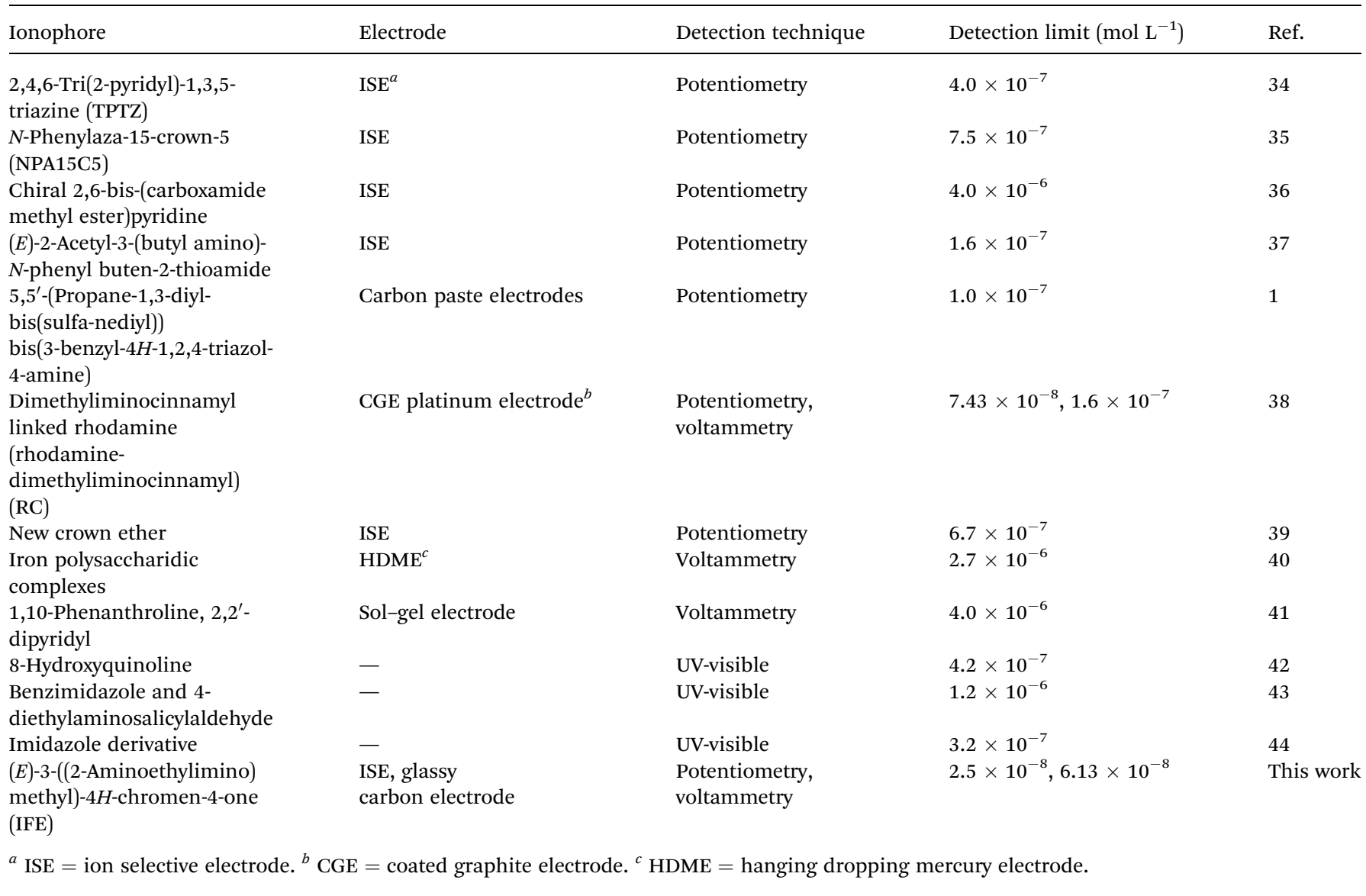

usefulness of proposed voltammetric and potentiometric sensor, these were employed in various real sample matrices such as a pharmaceutical samples and black tea. The results obtained from three replicate measurements given in Table 3 show that there is a satisfactory agreement between the results obtained using the Fe(II)-selective electrode and AAS.

\subsection{Comparison of performance characteristics with those of previously reported electrodes}

When compared with other electrochemical methods, the proposed method for $\mathrm{Fe}(\mathrm{II})$ determination shows better selectivity, wide linear concentration range and lower detection limit. The performance characteristics of proposed electrodes were compared with previously reported electrodes for the determination of $\mathrm{Fe}(\mathrm{II})^{1,34-44}$ and are summarized in Table 4.

\section{Conclusion}

Theory and experiments on a novel potentiometric and voltammetric sensors are reported for the determination of $\mathrm{Fe}(\mathrm{II})$ based on newly synthesized ionophore (E)-3-((2-aminoethylimino)methyl)-4H-chromen-4-one (IFE). The performance of liquid membrane electrode improved with the addition of MWCNT in the membrane matrix exhibited the detection limit of $2.5 \times 10^{-8} \mathrm{M}$. The analytical utility of the membrane electrode was validated by using it as indicator electrode and real life sample analysis for the determination of Fe(II). In addition, redox behavior of IFE was characterized by using the voltammetric technique. The chemical interaction of IFE with $\mathrm{Fe}^{2+}$ was supported by DFT studies on the ligand and the complex with the metal ion.

\section{Acknowledgements}

Authors are thankful to Director, Thapar University, Patiala for providing research facilities. We are also grateful to the Sophisticated Analytical Instrumentation Lab (SAI) for SEM and EDX facilities. Authors are thankful to Dr Jasminder Singh for help in synthesis of compounds and Dr Manmohan Chhibber, Associate Professor at TU for helpful discussions.

\section{References}

1 R. F. Aglan, M. S. Rizk, G. G. Mohamed, A. H. El-Wahy and H. A. Mohamed, Am. J. Anal. Chem., 2014, 5, 140.

2 E. M. Hulburt and J. Rodman, Limnol. Oceanogr., 1963, 8, 263-269.

$3 \mathrm{~J}$. P. Riley and R. Chester, Introduction to marine chemistry, Academic Press, London, New York, 1971.

4 J. H. Martin and S. Fitzwater, Nature, 1988, 331, 947-975. 
5 J. H. Martin, R. M. Gordon and S. E. Fitzwater, Nature, 1990, 345, 156-158.

6 F. A. Cotton and G. Wilkinson, Advanced inorganic chemistry, John Wiley \& Sons, New York, 1988.

7 A. Safavi and H. Abdollahi, Microchem. J., 1999, 63, 211-217. 8 Z. Zeng and R. A. Jewsbury, Analyst, 2000, 125, 1661-1665.

9 M. Gallego, M. Garcia-Vargas and M. Valcarcel, Analyst, 1979, 104, 613-619.

10 H. Kaasalainen, A. Stefansson and G. K. Druschel, Int. J. Environ. Anal. Chem., 2016, 96, 1074-1090.

11 D. Giokas, E. Paleologos, S. Tzouwara-Karayanni and M. Karayannis, J. Anal. At. Spectrom., 2001, 16, 521-526.

12 J. K. Huber, Analyst, 1999, 124, 657-663.

13 M. Murillo, Z. Benzo, E. Marcano, C. Gomez, A. Garaboto and C. Marin, J. Anal. At. Spectrom., 1999, 14, 815-820.

14 W.-K. Oh, Y. S. Jeong, S. Kim and J. Jang, ACS Nano, 2012, 6, 8516-8524.

15 V. K. Gupta, A. K. Singh and L. K. Kumawat, Sens. Actuators, B, 2014, 204, 507-514.

16 I. Randrianjatovo-Gbalou, E. Girbal-Neuhauser and C.-E. Marcato-Romain, Anal. Biochem., 2016, 500, 12-14.

17 Y. Zhang, G.-M. Zeng, L. Tang, C.-G. Niu, Y. Pang, L.-J. Chen, C.-L. Feng and G.-H. Huang, Talanta, 2010, 83, 210-215.

18 I. Yilmaz, H. Temel and H. Alp, Polyhedron, 2008, 27, 125132.

19 W. Al Zoubi and N. Al Mohanna, Spectrochim. Acta, Part A, 2014, 132, 854-870.

20 A. A. A. Aziz, J. Lumin., 2013, 143, 663-669.

21 N. M. Hosny, M. A. Hussien, F. M. Radwan and N. Nawar, Spectrochim. Acta, Part A, 2014, 132, 121-129.

22 A. Kuwar, R. Patil, A. Singh, S. K. Sahoo, J. Marek and N. Singh, J. Mater. Chem. C, 2015, 3, 453-460.

23 E. Bakker, P. Bühlmann and E. Pretsch, Chem. Rev., 1997, 97, 3083-3132.

24 Y. Umezawa, K. Umezawa and H. Sato, Pure Appl. Chem., 1995, 67, 507-518.

25 T. Sokalski, A. Ceresa, M. Fibbioli, T. Zwickl, E. Bakker and E. Pretsch, Anal. Chem., 1999, 71, 1210-1214.
26 R. Eugster, T. Rosatzin, B. Rusterholz, B. Aebersold, U. Pedrazza, D. Rüegg, A. Schmid, U. E. Spichiger and W. Simon, Anal. Chim. Acta, 1994, 289, 1-13.

27 M. a. d. l. A. A. Pérez, L. P. Marín, J. C. Quintana and M. Yazdani-Pedram, Sens. Actuators, B, 2003, 89, 262-268.

28 P. Bühlmann, E. Pretsch and E. Bakker, Chem. Rev., 1998, 98, 1593-1688.

29 P. Bühlmann, S. Yajima, K. Tohda and Y. Umezawa, Electrochim. Acta, 1995, 40, 3021-3027.

30 M. Telting-Diaz and E. Bakker, Anal. Chem., 2001, 73, 55825589.

31 T. Rosatzin, E. Bakker, K. Suzuki and W. Simon, Anal. Chim. Acta, 1993, 280, 197-208.

32 Y. Umezawa, P. Bühlmann, K. Umezawa, K. Tohda and S. Amemiya, Pure Appl. Chem., 2000, 72, 1851-2082.

33 G. Bereket, E. Hür and C. Öğretir, J. Mol. Struct.: THEOCHEM, 2002, 578, 79-88.

34 W. H. Mahmoud, Anal. Chim. Acta, 2001, 436, 199-206.

35 M. Aghaie, M. Giahi, H. Aghaie, M. Arvand, M. Pournaghdy and F. Yavari, Desalination, 2009, 247, 346-354.

36 M. Abounassif, M. Al-Omar, A. G. Amr and G. Mostafa, Drug Test. Anal., 2011, 3, 373-379.

37 M. A. Yazdely, M. A. Taher and S. Tajik, Anal. Bioanal. Electrochem., 2013, 5, 467-480.

38 A. Kamal, N. Kumar, V. Bhalla, M. Kumar and R. K. Mahajan, Sens. Actuators, B, 2014, 190, 127-133.

39 G. Absalan, M. Arabi, R. Khalifeh, H. Sharghi and J. Tashkhourian, IEEE Sens. J., 2014, 14, 349-356.

40 D. Merli, A. Profumo and C. Dossi, J. Pharm. Anal., 2012, 2, 450-453.

41 N. Y. Stozhko, E. Morosanova, L. Kolyadina and Z. M. Azarova, J. Anal. Chem., 2004, 59, 865-870.

42 N. Lashgari, A. Badiei and G. M. Ziarani, J. Fluoresc., 2016, 26, 1885-1894.

43 Y. S. Kim, J. J. Lee, S. Y. Lee, T. G. Jo and C. Kim, RSC Adv., 2016, 6, 61505-61515.

44 T. G. Jo, K. H. Bok, J. Han, M. H. Lim and C. Kim, Dyes Pigm., 2017, 139, 136-147. 